\title{
Introduction to the thematic section on the Economics of Ageing
}

MARIJANA BAĐUN, Ph.D.

ŠIME SMOLIĆ, Ph.D.

Guest editors' introduction

https://doi.org/10.3326/pse.42.3.1

Marijana BAĐUN

Institute of Public Finance, Smičiklasova 21, 10000 Zagreb, Croatia

e-mail: marijana.badjun@ijf.hr

ORCiD: 0000-0001-9645-1540

\section{Šime SMOLIĆ}

Faculty of Economics and Business, Trg J. F. Kennedyja 6, 10000 Zagreb, Croatia e-mail: ssmolic@efzg.hr ORCiD: 0000-0003-0920-8046 
In one of his books, fantasy author Terry Pratchett wrote that "inside every old person is a young person wondering what happened." Ageing does not seem to come as a surprise only to individuals, but to governments as well. Pension, healthcare and long-term care systems were all designed with a much smaller share of an elderly population in mind.

In the mid-twentieth century, the proportion of the world's population aged 65 years and over was $5 \%$, but by 2050 , it is expected to reach almost $16 \%$ (UN, 2017). At the global level, life expectancy at birth was 47 years in the mid-twentieth century and is expected to rise to 78 years by the mid-twenty-first century. In the European Union (EU), the share of the $65+$ population was already $19 \%$ in 2016, and it is predicted to increase to almost 29\% in 2050 (EC, 2018). Life expectancy at birth in the EU is expected to rise from 78 for men and 84 for women in 2016 to 84 for men and 88 for women in 2050 .

This issue of Public Sector Economics includes three articles that look specifically at topics linked to the economics of ageing. Topics include (a) perceptions and attitudes related to the pension system in the Federation of Bosnia and Herzegovina, (b) healthcare expenditure projections for Switzerland, and (c) informal long-term care analysis based the Survey on Health, Ageing and Retirement in Europe (SHARE) data for eleven European countries. Additionally, this issue of Public Sector Economics also contains a review of the book "Golden Aging: Prospects for Healthy, Active and Prosperous Aging in Europe and Central Asia", published by the World Bank, and a paper which is not directly related to the economics of ageing: "To what extent do fiscal spending rules affect budget composition" written by Wildmer Daniel Gregori.

The first article by Velma Pijalović, Lejla Lazović-Pita, Almir Peštek and Danijela Martinović, "The analysis of perceptions and attitudes related to ageing in the Federation of Bosnia and Herzegovina (FBIH)" is based on opinion survey data, with a special focus on the fact that an ageing population might be a problem for pension systems in the future. The results indicate that more than three quarters of the respondents are aware of this problem in FBIH. An additional logit regression model reveals that pensioners, respondents who prefer a primary role for government, those with higher levels of education and reported living standards are more likely to perceive this issue. Improvements in the efficiency of pension funds, reduction in public spending and active measures aimed at the prevention of emigration from FBIH are the most "popular" solutions in survey results. Interestingly, more than three quarters of citizens oppose raising the retirement age.

The second article "Healthcare expenditure and fiscal sustainability: evidence from Switzerland", written by Carsten Colombier and Thomas Braendle, looks into growing healthcare expenditure in terms of public finance sustainability. Switzerland has one of the most expensive healthcare systems among OECD countries. According to the authors' projections up to 2045, population ageing 
puts a growing pressure on public budgets and the mandatory healthcare insurance in Switzerland. However, healthcare expenditure is not only spurred by demographic change but also by non-demographic drivers such as the increasing national income, medical advances and Baumol's cost disease (lower productivity development in healthcare that leads to additional cost pressure). The authors find that long-term care is more strongly influenced than healthcare excluding longterm care. This result indicates that population ageing affects public finance to a larger extent than the mandatory healthcare insurance. Measures directed at prevention and efficiency would be the most helpful in alleviating the pressure on public finance and mandatory healthcare insurance.

The third article, by Andrej Srakar and Mateja Nagode, "Why are older informal carers in better health? Solving a causality problem" focuses on informal care, an important segment of long-term care. The authors look into the relationship between the health status of the SHARE respondents and the decision to provide informal help to others and the intensity of such assistance. SHARE is a multinational and multidisciplinary panel database of micro data on health and well-being, socioeconomic status and social and family networks of the population aged 50 and over. Interestingly, the authors find that the correlation of health and informal caregiving is negative, particularly for help provided within a household. However, once they apply regression analysis with instrumental variables from previous waves of the SHARE survey, they determine the causal effects of health on informal care, provided within and/or outside a household. The authors find that older people in better health tend to provide more help to others. Furthermore, giving help has negative effects on health of the provider. Adopting measures to stimulate the health of potential and actual caregivers would raise the level of provided help.

The report "Golden Aging: Prospects for Healthy, Active and Prosperous Aging in Europe and Central Asia (ECA)" discusses both the main challenges and opportunities of demographic trends in the countries of ECA, a region with the oldest populations in the world. The authors of (and contributors to) this report invested a tremendous effort in analysing one of the most striking topics of modern societies - population ageing. At the very beginning of this report, there is a crucial graph, indicating how the demographic drivers and economic consequences of aging create both challenges and opportunities. The report reveals not only the disadvantages but also many opportunities consequent upon demographic ageing in ECA countries. A journey towards "Golden Ageing" in ECA countries is within reach. However, it will require coordinated actions among different actors, including the government, the private sector, and societies, and across many areas, ranging from labour markets to health care to education and pensions.

The three segments (healthcare, long-term care and pension systems) covered in this issue of Public Sector Economics are naturally not the only topics under consideration in the economics of ageing, even though they are very important. Ageing 
poses many economic challenges, but Harper (2017) argues that we are trying to tackle the twenty-first century phenomenon of very long lives with twentieth century institutions. Additionally, as pointed out by Leeson (2017), redefining old age is necessary in order to realize and release the potential of ageing. In his opinion, people are constrained from contributing to their families, communities and workplaces for much longer, in their $70 \mathrm{~s}, 80 \mathrm{~s}$ and even $90 \mathrm{~s}$, by legislative and administrative age barriers. Let us conclude with another quotation: "Is old age really so terrible? Not if you've brushed your teeth faithfully" (Woody Allen). Ageing has its gloomy side, but it also creates many opportunities. 